\title{
CORRELATION OF NEUTROPHILLYMPHOCYTE RATIO WITH GLYCOSYLATED HB IN PATIENTS WITH TYPE 2 DIABETES MELLITUS.
}

V Sandeep Kumar

Aishwarya Ganga

S N.*

Anand A. S.
Senior Resident, Department of Pathology, Navodaya Medical College, Raichur, Karnataka, India.

Third year Postgraduate student,Department of Pathology, Navodaya Medical College, Raichur, Karnataka, India. *Corresponding Author

Professor and Head; Department of Pathology, Navodaya Medical College, Raichur, Karnataka, India.

ABSTRACT Introduction: Neutrophilic leukocytosis is directly associated with the pathogenesis of atherosclerosis in patients with diabetes mellitus (DM). Increased white blood cell (WBC) count is related to cardiovascular disease in patients with type 2 diabetes mellitus; raised neutrophil lymphocyte ratio (NLR) is associated with metabolic syndrome. concerning a correlation between glycosylated haemoglobin (HbA1c) and NLR. Aims and objectives: The aim of the present study was to investigate the neutrophils lymphocyte ratio (NLR) and blood glucose regulation in type 2 diabetes patients. Methods: This prospective study of 6 months duration was conducted in patients with type 2 diabetes mellitus, divided into two groups according to HbAlc levels. group 1 - HbA1c levels $\leq 7 \%$; group 2-HbA1c levels $>$ $7 \%$. WBC, neutrophil and lymphocyte counts were determined by automated analyser, HbA1C was calculated using Afinion 2. Results: Of total 50 patients included, Random blood glucose, neutrophil, WBC counts, NLR, HbA1C were significantly higher in group 2 compared to group 1.Conclusion:NLR of uncontrolled group ( $\mathrm{HbA} 1 \mathrm{c}>7 \%$ ) was significantly higher than that of controlled group $(\mathrm{HbA} 1 \mathrm{C}<7 \%)$. We conclude that NLR gives us very good and similar results to know the early complications of uncontrolled DM.

KEYWORDS : Neutrophil lymphocyte ratio, Glycosylated haemoglobin, Diabetes mellitus

\section{INTRODUCTION:}

Type 2 diabetes mellitus is a disease characterized by high levels of glucose in blood. India has been declared as diabetic capital of the world. According to the World Health Organization, at least 151 million people or $2.8 \%$ of the population were suffering from diabetes worldwide (2000). Its incidence is increasing rapidly and it is estimated that by the year 2030, this number will almost double. It is the seventh leading cause of death accounting $3.3 \%$ of total deaths.

In India reported prevalence of diabetes mellitus is around $8.9 \%$ and incidence of cardiovascular diseases in these patients is 30$39 \%$.Extreme high blood glucose level affects all parts of the body and promotes the development of different complications resulting from inflammation, such as neuropathy, retinopathy, renal failure, hypercoagulability, hypertension, myocardial infarction, stroke and peripheral vascular disease, among others. ${ }^{17}$ Increased risk of heart disease and stroke represents the leading cause of mortality in people with diabetes.

High blood glucose levels are toxic to the body, leading to protein glycation, hyper-osmolality and increased intracellular sorbitol levels. ${ }^{17}$ Glycation is an irreversible non-enzymatic binding reaction between glucose and a protein - e.g. hemoglobin, which give rise to the term glycated hemoglobin $(\mathrm{HbAlc}){ }^{6}$ Total $\mathrm{HbA} 1 \mathrm{C}$ corresponds to the molecules most negatively charged by the addition of glucose and other carbohydrates. The A1c fraction is present in $\mathrm{HbA} 1 \mathrm{c}$, with glucose attached to the $\mathrm{N}$-terminal valine of the beta chain.

Total White blood cell (WBC) count is linked to various components of metabolic syndrome. ${ }^{5}$ The count of white blood cell (WBC) is a basic and sensitive indicator of the inflammatory status. ${ }^{6}$ The increased number of circulating leukocytes not only reflects a presence of acute infection in the body but they have a dominant inflammatory role in the pathogenesis of different phases of atherosclerosis and leads to various cardiovascular disorders. ${ }^{19}$ Studies have shown that increased leukocyte counts are reliable markers of systemic inflammation and have diagnostic as well as prognostic value in patients of myocardial infarction, stroke, peripheral vascular disease and micro and macro vascular complication associated with type 2 diabetes mellitus patients. ${ }^{18}$

Among the multiple parameters of complete blood count, NLR has been studied extensively and has been suggested to be a prognostic marker in acute myocardial infarction, heart failure, and stroke. ${ }^{20}$ It reflects a counterbalance between two complementary components of the immune system; neutrophils being the active nonspecific mediator of inflammation, whereas lymphocytes acting as the protective or regulatory component of inflammation. ${ }^{17} \mathrm{An}$ increase in the number of neutrophils is associated with thrombus formation and ischemic injury. ${ }^{18}$ Lagof immune response to various physiological and pathological conditions in diabetes patient is characterized by increased neutrophils and decreased lymphocyte count. ${ }^{18}$ Neutrophil lymphocyte ratio (NLR) is often recognized as new indicator of subclinical inflammation in type 2 diabetes patient.

In addition to blood glucose, $\mathrm{HbA} 1 \mathrm{C}$ has become an important tool for diagnosing diabetes mellitus (DM), ensuring glycemic control and predicting the risk of vascular complications. ${ }^{18} \mathrm{NLR}$ was introduced as a novel marker to determine inflammation in cardiac and non-cardiac disorders .Hence this study is done to predict the risk of type 2 diabetes mellitus patients leading to cardiovascular diseases and achieve good clinical outcome. ${ }^{1}$

\section{OBJECTIVES:}

1) To Investigate neutrophil lymphocyte ratio and blood glucose level in type 2 diabetes patients.

2) To investigate the glycosylated $\mathrm{Hb}(\mathrm{HbAlC})$ in type 2 diabetes patients.

3) To correlate NLR with blood glucose levels and HbA1C.

Sample Size: 50

Design of the study :Prospective study (Correlational study).

Duration of the study: 6 months (November 2019 to May2020).

Inclusion criteria: 1. Type 2 diabetes mellitus patients.

2. Patients aged $>30$ years and $<70$ years are included in this study

\section{EXCLUSION CRITERIA:}

1. Patients of type 1 diabetes mellitus.

2. MODY (Maturity onset diabetes of the young).

3. Patients with infection, malignancy and gestational diabetes mellitus.

4. Patients $<30$ and $>70$ years are excluded.

\section{MATERIALAND METHODS:}

- After medical/ethical committee approval, type 2 diabetes patients have been included at Navodaya medical college, Raichur and they will be advised for an overnight fasting.

- Patient consent was taken and explained about the study protocol and associated investigations.

- Under aseptic precautions venous blood samples (2-2.5 ml) were collected into haemogram tubes containing di-potassium ethylene-diamine-tetra-acetic acid and plane tubes.

- Samples were tested as soon as possible to minimize variations due to sample aging. 
- Total WBC, neutrophils and lymphocyte, $\mathrm{Hb}$ and platelet count were done by using an automated blood cell counter (SYSMYX XP-100).

- NLRs were quantified as total neutrophils counts divided by lymphocyte counts.

- HbA1c levels were measured using automated machine (AFINION 2).

- Serum glucose levels were measured using a hexokinase enzymatic method.

\section{RESULTS:}

Total 50 cases were included in the study and diagnostic criteria for diabetes mellitus, normal range of haematology parameters, normal values of absolute neutrophils count and absolute lymphocyte count are adopted from WHO guidelines, which is as follows.

1. RBS- $>11.1 \mathrm{mmol}$ or $>200 \mathrm{mg} / \mathrm{dl}$

2. $\mathrm{FBS}->7.00 \mathrm{mmol}>126 \mathrm{mg} / \mathrm{dl}$

3. $\mathrm{HbA} 1 \mathrm{C}->7 \%$.

Normal range of haematological parameters :

\begin{tabular}{|l|l|l|}
\hline & Range & Percentage \\
\hline Neutrophils & $1500-8000(1.5-8 \mu \mathrm{L})$ & $45-75 \%$ \\
\hline Lymphocytes & $1000-4000(1.0-4 \mu \mathrm{L})$ & $20-40 \%$ \\
\hline Leucocytes & $4.00-11.00 \times 10^{9 / 1}$ & \\
\hline
\end{tabular}

$\mathrm{HbA} 1 \mathrm{C}$ levels in selected patients were broadly divided into 2 groups $\mathrm{HbA} 1 \mathrm{C}<7$ considered as group 1 and $\mathrm{HbA} 1 \mathrm{C}>7$ considered as group 2.21/ 50 patients had $\mathrm{HbA} 1 \mathrm{C}<7$ and their $\mathrm{HbA} 1 \mathrm{C}$ value ranged from 5.4 to $7.0 \%$ with mean $\mathrm{HbA} 1 \mathrm{C}$ of this group was $6.5 \%$ and they were in good control. 29/50 patients of group 2 had $\mathrm{HbA} 1 \mathrm{C}>7$ with values of $\mathrm{HbA} 1 \mathrm{C}$ ranged from 7.2 to 9.9 with mean $\mathrm{HbA} 1 \mathrm{C}$ of this group was $9.4 \%$ and they were in poor control. Laboratory parameters such as RBS, Leucocytes, Neutrophils, lymphocytes, Haemoglobin, N/L ratio mean were compared between 2 groups and results obtained.

\section{(Table-1).GROUP1:}

\begin{tabular}{|c|c|c|}
\hline Normal & Normal & Abnormal \\
\hline $\mathbf{2 1 / 2 1}$ & $14 / 21$ & $7 / 21$ \\
\hline WBC:5000- & Neutrophils:56-77\% & Neutrophil-77-85\% \\
\hline RBS:82-180mg/dl & Lymphocyte: $16-38 \%$ & Lymphocyte: $14-19 \%$ \\
\hline HB:8-14mg/dl & N/L Ratio: $1.4-3$ & N/L Ratio: $4-5.7 \%$ \\
\hline
\end{tabular}

Out of 21 patients in group 1,7/21 patients come under the age group of 40-50yrs and 14/21 patients come under the age group of 50-60 years and 21 patients had controlled parameters WBC counts ranges from 5000-11,000 with mean 7500, haemoglobin ranges from 8$14 \mathrm{mg} / \mathrm{dl}$ with mean of $11.4 \mathrm{mg} / \mathrm{dl}$, RBS ranges from $82-180$ with mean of 155 and $14 / 21$ patients neutrophils counts ranges from $56-77 \%$ with mean of $70.14 \%$, lymphocyte ranges from $16-38$ with mean $22.4 \%$ and $\mathrm{N} / \mathrm{L}$ ratio ranges from $1.4-3.0$ with mean of 2.52 above all patients have controlled parameters. $7 / 21$ patients whose neutrophils ranges from $77-85 \%$ with mean $78.9 \%$ and lymphocyte ranges from $14-19$ with mean $17.5 \%$. N/L ratio ranges from $4-5.7$ with mean 5.4 , these patients were having abnormal values of above mentioned parameters.

GROUP 2:

\begin{tabular}{|l|l|l|}
\hline Abnormal(29/29) & Abnormal(12/29) & Normal(17/29) \\
\hline WBC: $11200-1400 \times 10 \% / 1$ & WBC:11200-14000 & WBC: $6500-11000$ \\
\hline Neutrophils: $77-85 \%$ & & \\
\hline Lymphocytes-11-19\% & & \\
\hline Hb:8-15mg/dl & & \\
\hline RBS: $160-418 \mathrm{mg} / \mathrm{dl}$ & & \\
\hline N/L Ratio:3.9-7.6 & & \\
\hline
\end{tabular}

Group 2 includes 29 patients and their age group vary from 30-60 years and they had abnormal values of all above mentioned parameters i.e 29 patients neutrophils ranges from $77 \%-85 \%$ with mean of $80.76 \%$, lymphocyte ranges from $11 \%-19 \%$ with mean of $17.2 \%$, haemoglobin ranges from $8-15 \mathrm{mg} / \mathrm{dl}$ with mean $12.2 \mathrm{mg} / \mathrm{dl}$, RBS ranges from from $160-418$ with mean of $230, \mathrm{~N} / \mathrm{L}$ ratio ranges from 3.9-7.6 with mean of 5.02. 12/29 patients WBC ranges from 11200-14000 with mean 12300 are also having abnormal parameters and 17 patients who had normal WBC counts which ranges from 6500-11000 with mean of 7500 .

In table 1 we are comparing all above mentioned haematological parameters between both groups to know the significance of each parameter in patients with controlled and uncontrolled group.
In group one WBC ranges from 5000-11,000 and group 2 ranges from $11200-14000$ and their mean $7,500 \pm 2280,10,286 \pm 2125.62$ respectively. WBC was found to be ranging between 5000-8100, 870012000 and 12200-14000 among patients with HbA1c value of $<7 \%$, between $>7$ to $9 \%$ and $>9 \%$ respectively. WBC significantly higher in group 2 as compare to group 1 as $\mathrm{HbA} 1 \mathrm{C}$ level increases WBC value keep on increasing and it is statistically significant with $\mathrm{p}$ value $<0.001$. Neutrophils in group 1 ranges from $56-77 \%$ and in group 2 ranges from $77 \%-85 \%$ and their mean $70.14 \% \pm 6.79,80 \pm 2.936$ respectively. The neutrophils was found to be $56 \%-81 \%, 78-85 \%$ and $77-85 \%$ among subjects with HbA1c value of less than $7 \%$, between 7 to $9 \%$ and more than $9 \%$ respectively. According to our study neutrophils is markedly increased in group 2 than group 1 and this also shows statistically significant with $p$ value $<0.001$.Lymphocytes in group 1 ranges from $16-38 \%$ and group 2 it is from $11 \%-19 \%$ and their mean $22.43 \pm 5.946,17.28 \pm 3.96$ respectively, lymphocytes found to be $16-38,15-25$ and 12-15 among subjects with $\mathrm{HbA} 1 \mathrm{C}$ value of $<7 \%, 7$ $9 \%$ and $>9 \%$ respectively and lymphocytes found be decreasing as $\mathrm{HbA} 1 \mathrm{C}$ level increasing it is statistically significant with $\mathrm{p}$ value $<$ 0.0021 .

RBS in group 1 ranges from 82 - 180 and group 2 it is from 160-449 and their mean of 155,218 respectively, RBS found to be $82-180,118-200$ and 211-449among subjects with $\mathrm{HbA1C}$ value of $<7 \%, 7-9 \%$ and $>9 \%$ respectively and RBS found be increasing in group 2 as compare with group 1 and its shows statistically significant with $p$ value $<0.031$.

NL ratio in group 1 ranges from 1.4-5.7 and group 2 it is from 3.9-7.6 and their mean of $3.52,5.02$ respectively. NL ratio found to be 1.4-3.9, 4.0-5.8 and 6-7.6among patients with $\mathrm{HbA} 1 \mathrm{C}$ value of $<7 \%, 7-9 \%$ and $>9 \%$ respectively and NL ratio was found to be increasing among the subjects with increase in $\mathrm{HbA} 1 \mathrm{C}$ levels. With p value $<0.001$ which is statistically significant.

Haemoglobin in group 1 ranges from 8-14 and group 2 it is from 9$15 \mathrm{mg} / \mathrm{dl}$-and their mean of $11.4 \mathrm{mg} / \mathrm{dl}, 12.2 \mathrm{mg} / \mathrm{dl}$ respectively, $\mathrm{Hb}$ found to be $8-13.5 \mathrm{mg} / \mathrm{dl}, 9-14.4 \mathrm{mg} / \mathrm{dl}$ and $9-12 \mathrm{mg} / \mathrm{dl}$ among patients with $\mathrm{HbA} 1 \mathrm{C}$ value of $<7 \%, 7-9 \%$ and $>9 \%$ respectively and in group 1,16 patients had normal $\mathrm{Hb}$ value and 5 of them had abnormal $\mathrm{Hb}$ value and the value of haemoglobin is not decreasing as the $\mathrm{HbA} 1 \mathrm{C}$ increases and $\mathrm{Hb}$ rangeis varying in both groups which is not correlating with $\mathrm{HbA} 1 \mathrm{C}$ value and it is not statistically significant with $\mathrm{p}$ value $>0.05$.

Neutrophils, lymphocyte, RBS, WBC counts and N/L ratio were statistically significant with $\mathrm{p}<0.05$ and haemoglobinis statistically not significant between 2 groups (Table 1).

Analysis using pearson's correlation coefficient showed that NLR correlated positively with HbA1C levels $(r=0.564, p=0.000$ $<0.007$,Figure 1).

A Linear regression analysis was also carried out using the enter method to evaluate the correlation between $\mathrm{HbA1C}$ with other haematological parameters measurement of $\mathrm{HbA} 1 \mathrm{C}$ taken as dependent parameters, wherasage, sex, WBC, neutrophils, lymphocyte, $\mathrm{Hb}$, RBS, NL ratio were independent parameters as shown in (Table-2) the results showed that WBC count and RBS independently associated with $\mathrm{HbA1C}$ with $\mathrm{p}$ value $(0.042,0.020$ respectively).(Table-2)

\begin{tabular}{|l|l|l|l|}
\hline Parameter & HBA1C $(<=7)$ & HBA1C $(>7)$ & $\begin{array}{l}\text { Statistical } \\
\text { Significance }\end{array}$ \\
\hline TLC & $\mathbf{7 5 0 0 . 4 8}$ & $\mathbf{1 0 2 8 6 . 2 1 ~ 2 1 2 5 . 6 2}$ & $\mathbf{P}<\mathbf{0 . 0 0 1}$ \\
Neutrophil & $\mathbf{2 2 8 0 . 2 4}$ & $\mathbf{8 0 . 7 6} 2.936$ & $\mathbf{P}<\mathbf{0 . 0 0 1}$ \\
Lymphocyte & $\mathbf{7 0 . 1 4} 6.799$ & $\mathbf{1 7 . 2 8} 3.963$ & $\mathbf{P}<\mathbf{0 . 0 0 2 1}$ \\
Hemoglobin & $\mathbf{2 2 . 4 3} 5.946$ & $\mathbf{1 2 . 0 2} 2.19$ & $\mathbf{P}>\mathbf{0 . 0 5}$ \\
RBS & $\mathbf{1 1 . 6 4 1 . 3 8}$ & $\mathbf{2 2 6 . 7 9} 71.45$ & $\mathbf{P}<\mathbf{0 . 0 3 1}$ \\
NL Ratio & $\mathbf{1 5 5 . 1 9} 28.15$ & $\mathbf{5 . 0 2} 1.29$ & $\mathbf{P}<\mathbf{0 . 0 0 1}$ \\
& $\mathbf{3 . 5 2} 1.22$ & & \\
\hline
\end{tabular}

Table 1-Hemogram data for patients with TYPE 2 diabetes mellitus divided into 2 group according to $\mathrm{HbA1C}$ levels: Group $1<7 \%$, and Group $2>7 \%$.

Statistically significant $(\mathrm{p}<0.05)$ and statistically not significant $\mathrm{p}>0.05$. 


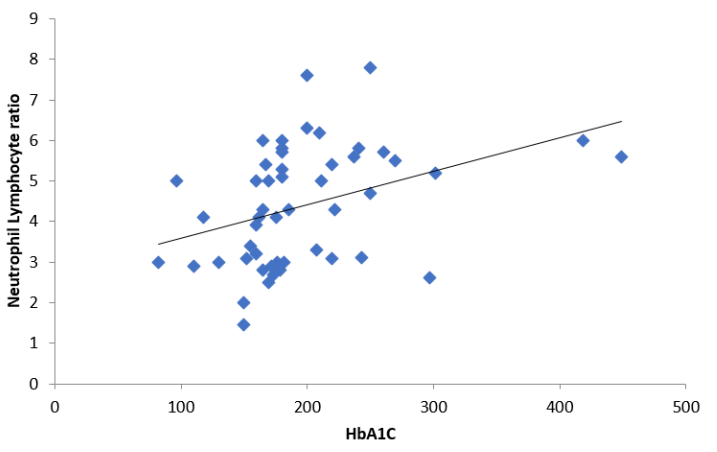

Figure-1: Scatter plot showing a positive correlation between neutrophil ,lymphocyte ratio and serum glcosylated haemoglobin (HbA1C) levels in 50 patients with type 2 diabetes mellitus.

Table 2: Linear regression analysis of factors related to $\mathrm{HbA1C}$ levels in 50 patients with type 2 diabetes mellitus.

\begin{tabular}{|l|l|l|l|l|l|}
\hline Characteristic & \multirow{2}{*}{$\boldsymbol{\beta}$} & \multirow{2}{*}{ odds ratio } & 95.0\% C.I & \multirow{2}{*}{ P Value } \\
\cline { 4 - 5 } & & & Lower & Upper & \\
\hline Age & 0.027 & 1.028 & 0.908 & 1.163 & 0.667 \\
\hline Sex & 1.249 & 3.487 & 0.275 & 44.232 & 0.335 \\
\hline TLC & 0.001 & 1.001 & 1.000 & 1.002 & $\mathbf{0 . 0 4 2}$ \\
\hline Neutrophil & 0.113 & 1.119 & 0.676 & 1.853 & 0.661 \\
\hline Lymphocyte & 0.258 & 1.294 & 0.762 & 2.198 & 0.340 \\
\hline Hb & -0.096 & 0.908 & 0.484 & 1.704 & 0.764 \\
\hline RBS & 0.058 & 1.060 & 1.009 & 1.113 & $\mathbf{0 . 0 2 0}$ \\
\hline NL ratio & 0.853 & 2.346 & 0.294 & 18.702 & 0.421 \\
\hline
\end{tabular}

\section{DISCUSSION:}

In our study we have found that patients who are categorised in group 2 (unregulated diabetes mellitus) are showed abnormal parameters of both neutrophils and lymphocytes.(i.e increased neutophil, decreased lymphocytes.)these findings are consistent with the study done by Khodabandehlou $\mathrm{T}$ et al ${ }^{1}$ in which lymphocytes levels were found to be reduced due to hyperglycemia. Previous study done by S.R.Ommen et $\mathrm{al}^{2}$ showed that low lymphocyte count served as an early marker of physiologic stress and systemic collapse secondary to myocardial ischemia mediated by cortisol release. Increased cortisol levels result in a reduction in the relative level of lymphocytes.

Study done by azabet $\mathrm{al}^{3}$ identified a higher rate of major cardiovascular events in diabetic patients with NLR $>2.36$ in a 4 year follow-up and a higher risk of progression of diabetic nephropathy. A similar negative impact on cardiovascular outcomes was found by lee et $\mathrm{al}^{4}$ in a large population of post myocardial infarction patients, but only among diabetics. In our study we found that neutrophilslymphocyte ratio was found to be increasing among the subjects with increase in HbA1c Levels. The Ratio was found to be 1.47-5, 2.9-5.8 and 5.1-7.6 among patients with HbA1c value of less than $7 \%, 7$ to $9 \%$ and $>9 \%$ respectively.

Study done by sefilet $\mathrm{al}^{5}$ found a positive association between NLR and glycosylated $\mathrm{hb}(\mathrm{HbA} \mathrm{cc})$ albeit in a small population of diabetics with poor glycemic control. ${ }^{5}$ However in contrast to our present data verodia et $\mathrm{al}^{6}$, found that significant increase in NLR directly correlate with glucose level but not with HbA1C.

The role of White Blood cells in estimating the glycaemic control was found to be statistically significant in our study which shows level of WBC found to be higher among the patients who had poor to worst control of diabetics. Another study done by Tsai JC et al in which patients were grouped based on the number of metabolic syndrome components, found a similar correlation between WBC count and $\mathrm{HbA1C}$.Same as our study the results of vozarova et $\mathrm{al}^{8}$ showed that a high WBC count is a predictive factor for the development of T2DM complications, thus low grade chronic inflammation may play an important role in the progression to $\mathrm{T}^{\mathrm{DMM}}{ }^{8}$ Ohshita et $\mathrm{al}^{9}$ showed increased WBC count in patients with impaired glucose tolerance. The increase in WBC mainly reflects the elevated neutrophils count in these studies. Study conducted bySefilet $\mathrm{al}^{5}$, Khodabandehlou T et $^{1}{ }^{1}$ found no association of WBC count with the glycemic control.

Our study showed that blood glucose level correlating with HbA1Ci.e patients of group 2 had increaseglucose level than group 1. Contrast to our study M Rosediani, MMed et $\mathrm{al}^{10}$ found in his study that correlation between plasma glucose profile with $\mathrm{HbA} 1 \mathrm{C}$, they found that $\mathrm{HbA1C}$ was better correlated to postprandial glucose levels than fasting plasma glucose, with moderate correlation ( $\mathrm{r}=0.604$ vs. 0.575$)$. The finding of postprandial glucose levels being better correlated to $\mathrm{HbA1C}$ than fasting glucose levels are supported by the study of Avignon et $\mathrm{al}^{11}$ Soonthornpun et $\mathrm{al}^{12}$ also concluded that strong correlation with $\mathrm{HbAlc}$ value was seen with 2-hour postprandial PG $(\mathrm{r}=\mathrm{O} .51)$ for near normal $\mathrm{FPG}(\mathrm{FPG}<7.8 \mathrm{mmollL})$.

In our study linear regression analysis reveled that RBS independently associated with $\mathrm{HbA} 1 \mathrm{C}$. Multiple linear regression analysis done by $\mathrm{M}$ Rosediani, MMed et al ${ }^{10}$ demonstrated that post lunch plasma glucose and extended post lunch plasma glucose correlated significantly and independently with $\mathrm{HbAlC}$, but the pre-breakfast plasma glucose and pre lunch plasma glucose did not.Bastyreta $1^{13}$ also reported similar findings with stronger correlation of 2-hour postprandial blood glucose with $\mathrm{HbA1C}$. $(\mathrm{r}=0.400, \mathrm{p}<0.001)$.

Our study shows that there is no correlation between haemoglobin in 2 groups and it is not statistically significant butcontrast to our data, study done by Jéssica Barbieri, et al ${ }^{14}$ It was observed that there are decreased values of hemoglobin, hematocrit, and red blood cells in anemic patients, which can be associated with a normocytic normochromic anemia, characteristic of an anemia of chronic disease (ACD) in type 2 diabetes patients. A retrospective study done by Yang, $\mathrm{J}$ et al ${ }^{12}$ in a cohort of patients with T2DM suggested that a lower level of $\mathrm{Hb}$ was associated with an increased risk of diabetic complications.

\section{CONCLUSION:}

In our study neutrophils lymphocytes ratio of uncontrolled group was significantly higher than that of controlled group. Results of our study showed that as HbA1C levels increasing, neutrophils levels also increases with decrease of lymphocytes in most of the uncontrolled group patients. Some of the uncontrolled group patients also showed increased level of $\mathrm{WBC}$ as $\mathrm{HbA} 1 \mathrm{C}$ level increases, so considering above all findings we conclude that N/L Ratio gives us very good and similar results to know the early complications of uncontrolled diabetic patients and it will be helpful to get good clinical outcome.

\section{REFERENCE:}

1. Khodabandehlou $\mathrm{T}$ Zhao H, Vimeux M, et al hematological consequence of hyperglycemic spike in healthy volunteers and insulin-dependent diabetics. Clin Hemorhoel Microcric 1998;19:105-114.

2. Ommen SR, Gibbons RJ, Hodge DO, Thomson SP. Usefulness of the Lymphocyte Concentration as a Prognostic Marker in Coronary Artery Disease. American journal of cardiology,vol.86,no.4, pp. 449-451, 2000

3. Azab B, Chainani V, Shah N, McGinn JT. Neutrophil-lymphocyte ratio as a predictor of major adverse cardiac events among diabetic population; a 4year follow-up study. Angiology 2013;64:456-65.

4. Lee GK, Lee LC, Chong E, Lee CH, Teo SG, Chia BL, et al. The long-term predictive Lee GK, Lee LC, Chong E, Lee CH, Teo SG, Chia BL, et al. The long-term predictive
value of the neutrophil-to-lymphocyte ratio in Type 2 diabetic patients presenting with

5. Sefil F, Ulutas K., Dokuyucu R, Sumbul, A, Yengil E, Yagiz AE, et al. Investigation of neutrophil lymphocyte ratio and blood glucose regulation in patients with type 2 diabetes mellitus. J Int Med Res 2014;42:581-8.

6. Verdoia M, Schaffer A, Barbieri L, Aimaretti G, Marino P, Sinigaglia F, Suryapranata H and De Luca G. Impact of diabetes on neutrophil-to-lymphocyte ratio and it relationship to coronary artery disease. Diabetes \& Metabolism. 2015;41(4).304-311. Tsai J, Sheu S, Chiu H, Chung F, Chang D, Chen M, Shin S, and Lee Y. Association of peripheral total and differential leukocyte counts with metabolic syndrome and risk of peripheral total and difor tis Dine

8. BarboraVozarova, Christian Weyer, Robert S Lindsay, Richard E Pratley, Clifton Bogardus, P Antonio Tataranni. High White Blood Cell Count Is Associated With Worsening of Insulin Sensitivity and Predicts the Development of Type 2 Diabetes. 2002;51(2) $455-61$

9. Ohshita K, Yamane K, Hanafusa M, Mori H, Mito K, Okubo M, et al. Elevated white blood cell count in subjects with impaired glucose tolerance. Diabetes Care. 2004;27(2):491-496.

10. Rosediani M,Azidah AK, Mafauzy M. Correlation between fasting plasma glucose, post prandial glucose and glycated haemoglobin and fructosamine. Med J Malaysia. 2006;61(1):67-71.

11. Avignon A, Radaucenu A, Monnier 1. Nonfasting plasma glucose is a better marker of diabetic control than fasting plasma glucose in type 2 diabetes. Diabetes Care 1997; 20 : 1822-826.

12. Soonthornpun S, Rattarasarn C, Leelawattana R, Setasuban W. Postprandial plasm glucose: a good index of glycemic control in type 2 diabetic patients having near-normal glucose: a good index of glycemic control in type 2 diabetic pa
fasting glucose levels. Diabetes Res ClinPract 1999; 46: 23-27.

13. Bastyr EJ III, Stuart CA, Brodows RG. (IORZ Study Group). Therapy focused on lowering postprandial glucose, not fasting glucose, may be superior for lowering HbAlc. Diabetes Care 2000; 23: 1236-41.

14. Barbieri J, Fontela P, Winkelmann E, Zimmermann C, Sandri Y, Mallet E. and Frizzo M. Anemia in Patients with Type 2 Diabetes Mellitus. Anemia, 2015, pp.1-7.

15. Yang, J., Yan, P. J., Wan, Q., \& Li, H. (2017). Association between Hemoglobin Levels and Diabetic Peripheral Neuropathy in Patients with Type 2 Diabetes: A Cross-Sectiona Study Using Electronic Health Records. Journal of diabetes research, 2017, 2835981

16. Zimmet P, Alberti K, Shaw J. Global and societal implications of the diabetes epidemic. Nature. 2001;414:782-7.

17. Mendes BB, Oliveira ACR, Alcântara KC. Comparison of the neutrophil-to-lymphocyte and platelet-to-lymphocyte ratios in normoglycemic and hyperglycemic subjects. and platelet-to-lymphocyte ratios in normoglycemic and hype
Einstein (Sao Paulo). 2019;17(1):eAO4403. Published 2019 Jan 14. 
18. Lou, M., Luo, P., Tang, R. et al. Relationship between neutrophil-lymphocyte ratio and insulin resistance in newly diagnosed type 2 diabetes mellitus patients. BMC Endocr Disord 15,9(2015).

19. Hussain M, Babar MZM, Akhtar L, Hussain MS. Neutrophil lymphocyte ratio (NLR): A well assessment tool of glycemic control in type 2 diabetic patients. Pak J Med Sci. 2017;33(6):1366-1370. doi:10.12669/pjms.336.12900

20. Dutta, D., Chittawar, S., Qureshi, Z., Surana, V., Khandare, S. and Dubey, T., 2017. Neutrophil-lymphocyte ratio is a novel reliable predictor of nephropathy, retinopathy, and coronary artery disease in Indians with type-2 diabetes. Indian Journal of Endocrinology and Metabolism, 21(6), p.864 